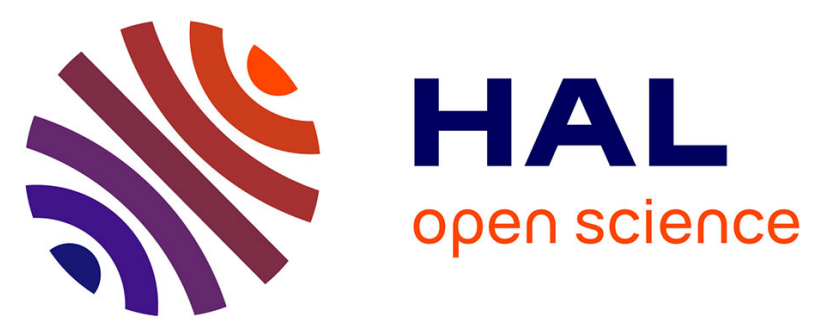

\title{
Higher Anti-Tumor Efficacy of the Dual HER3-EGFR Antibody MEHD7945a Combined with Ionizing Irradiation in Cervical Cancer Cells
}

\author{
Laura Bourillon, Sylvain Demontoy, Alexis Lenglet, Alexandre Zampieri, \\ Julien Fraisse, Marta Jarlier, Florence Boissière-Michot, Hélène Perrochia, \\ Gauthier Rathat, Véronique Garambois, et al.
}

\section{To cite this version:}

Laura Bourillon, Sylvain Demontoy, Alexis Lenglet, Alexandre Zampieri, Julien Fraisse, et al.. Higher Anti-Tumor Efficacy of the Dual HER3-EGFR Antibody MEHD7945a Combined with Ionizing Irradiation in Cervical Cancer Cells. International Journal of Radiation Oncology, Biology, Physics, 2020, 106 (5), pp.1039-1051. 10.1016/j.ijrobp.2019.12.020 . hal-03038992

\section{HAL Id: hal-03038992 https://hal.science/hal-03038992}

Submitted on 3 Dec 2020

HAL is a multi-disciplinary open access archive for the deposit and dissemination of scientific research documents, whether they are published or not. The documents may come from teaching and research institutions in France or abroad, or from public or private research centers.
L'archive ouverte pluridisciplinaire HAL, est destinée au dépôt et à la diffusion de documents scientifiques de niveau recherche, publiés ou non, émanant des établissements d'enseignement et de recherche français ou étrangers, des laboratoires publics ou privés. 


\section{Higher anti-tumor efficacy of the dual HER3-EGFR antibody MEHD7945A combined with ionizing irradiation in cervical cancer cells}

Laura Bourillon ${ }^{1}$, Sylvain Demontoy, $\mathrm{MD}^{2 *}$, Alexis Lenglet, MD ${ }^{2 *}$, Alexandre Zampieri ${ }^{1}$, Julien Fraisse $^{2}$, Marta Jarlier ${ }^{2}$, Florence Boissière ${ }^{1}$, Hélène Perrochia, MD ${ }^{4}$, Gauthier Rathat, MD ${ }^{4}$, Véronique Garambois ${ }^{1}$, Nathalie Bonnefoy, $\mathrm{PhD}^{1}$, Henri-Alexandre Michaud, $\mathrm{PhD}^{1}$, Thierry Chardès, PharmD, $\mathrm{PhD}^{1}$, Diego Tosi, $\mathrm{MD}, \mathrm{PhD}^{1,2}$, André Pèlegrin, $\mathrm{PhD}^{1}$, David Azria, $\mathrm{MD} \mathrm{PhD}^{1-3}$, Christel Larbouret, $\mathrm{PhD}^{1}$, Céline Bourgier, $\mathrm{MD} \mathrm{PhD}^{1-3}$

${ }^{1}$ IRCM, Institut de Recherche en Cancérologie de Montpellier, INSERM U1194, Université de Montpellier, Institut régional du Cancer de Montpellier, Montpellier, F-34298, France

${ }^{2}$ Institut régional du Cancer de Montpellier (ICM), Val d'Aurelle, Montpellier, F-34298, France

${ }^{3}$ Faculté de médecine, Université de Montpellier, Montpellier, F-34298, France

${ }^{4} \mathrm{CHU}$ Arnaud de Villeneuve, Montpellier, France

* Equal contribution

Corresponding Author: Celine Bourgier, ICM-Val d'Aurelle/ Institut de Recherche en Cancérologie de Montpellier, Campus ICM, 34298 Montpellier Cedex 5, France; E-mail: celine.bourgier@icm.unicancer.fr ; phone: 33 (0) 467612519; Fax: 33 (0) 467613787.

Funding: This work was supported by grants from the SIRIC Montpellier Cancer «INCa-DGOSINSERM $6045 »$; a Material Transfer Agreement was made between the Institut Régional du Cancer de Montpellier ("Institution") and Genentech Inc., South San Francisco, CA 94080, USA.

Conflicts of interest: The authors declare no conflict of interest.

Running title: MEHD7945A enhances response to ionizing radiation in preclinical cervix cancer models

Acknowledgments: Elisabetta Andermarcher for English editing 


\section{SUMMARY}

Targeting EGFR and HER3 with a specific dual antibody (MEHD7945A) enhanced irradiation efficacy in vitro (cervical cancer cell lines) and in vivo (xenografted mice) in an additive way. Moreover, our study suggests that co-expression of EGFR and HER3 could be a candidate prognostic biomarker of poor overall survival in patients with cervical cancer. These preliminary results should be confirmed in a study with a larger sample. 


\begin{abstract}
Purpose: The outcome of locally advanced cervical cancer (LACC) is dismal. Biomarkers are needed to individualize treatments and to improve patient outcome. Here, we investigated whether co-expression of EGFR and HER3 could be an outcome prognostic biomarker, and whether targeting both EGFR and HER3 with a dual antibody (MEHD7945A) enhanced ionizing radiation (IR) efficacy.
\end{abstract}

Methods and Materials: Expression of EGFR and HER3 was evaluated by immunohistochemistry in cancer biopsies ( $n=72$ patients with LACC). The antitumor effects of the MEHD7945A and IR combotherapy were assessed in two EGFR/HER3-positive cervical cancer cell lines (A431 and CaSki), and in A431 cell xenografts. The mechanisms involved in tumor cell radiosensitization were also studied. The interaction of MEHD7945A, IR and cisplatin was evaluated using doseresponse matrix data.

Results: EGFR and HER3 were co-expressed in only in 7 of the 22 biopsies of FIGO IVB cervix cancer. The median overall survival was 14.6 months and 23.1 months in patients with FIGO IVB tumors that co-expressed or not EGFR and HER3, respectively. In mice xenografted with A431 (squamous cell carcinoma) cells, MEHD7945A significantly increased IR response by reducing tumor growth and by increasing cleaved caspase 3 expression. In A431 and CaSki cells, the combotherapy increased DNA damage and cell death, particularly immunogenic cell death, and decreased survival by inhibiting the MAPK and AKT pathways. An additive effect was observed when IR, MEHD7945A and cisplatin were combined.

Conclusions: Targeting EGFR and HER3 with a specific dual antibody enhanced IR efficacy. These preliminary results should be confirmed in a larger sample, as well as the hypothesis that EGFR/HER3 co-expression might be a negative prognostic marker. 


\section{INTRODUCTION}

Cervical cancer represents the second most frequent malignancy in women worldwide, especially in developing countries. Radiotherapy in combination with cisplatin (as radiosensitizer) is the goldstandard therapy for the locoregional management of cervical cancer, and has significantly improved patient outcome. However, a high relapse risk still persists and leads to poor overall survival (OS) (5-year OS rate: 70\%) (1-3).

Many publications have suggested the implication of the epidermal growth factor receptor (EGFR) pathway in cervical cancer via EGFR overexpression or amplification, often in association with other EGFR family members, such as HER2, 3 and 4. EGFR or HER3 overexpression in locally advanced cervical cancer (LACC) is correlated with poor prognosis (4-8). Emerging evidences indicate that HER3 overexpression contributes to the acquired resistance to EGFR and HER2 targeted therapy by activating downstream pathways $(9,10)$, and also to carcinoma cell survival following radiation $(11,12)$. Preclinical studies on the association of MEHD7945A, a dual humanized IgG1 antibody targeting HER3 and EGFR, with ionizing radiation (IR) showed radiosensitization in head and neck $(\mathrm{HN})$ and non-small cell lung cancer models $(13,14)$. MEHD7945A safety, pharmacokinetics, pharmacodynamics and antitumor activity were assessed in a phase I study in which no dose limiting toxicity (DLT) was observed (15). When combined with chemotherapy (cisplatin/5-fluorouracil or carboplatin/paclitaxel) in patients with $\mathrm{HN}$ recurrent/metastatic squamous cell cancer (16), DLT was recorded in four patients, and the chemotherapy dose was reduced in 19 of 24 patients.

Here, we first assessed whether EGFR and HER3 are co-expressed in cervical cancer biopsy samples, and then we used in vitro and in vivo cervical cancer models to determine whether the IRMEHD7945A combination could be a relevant strategy for patients with cervical cancer showing EGFR-HER3 co-expression. 


\section{METHODS AND MATERIALS}

\section{Clinical and biological database}

A clinical database was retrospectively generated using the data of all patients $(n=75)$ with cervical epidermoid carcinoma referred to xxx University Hospital from October 2001 to October 2014. Expression of EGFR and HER3 was analyzed by immunohistochemistry on all biopsies at diagnosis $(n=72)$ and scored using the H-score. Additional details are in Supplementary Materials and Methods. The patients' and tumor characteristics are listed in Table 1. This study was approved by the Hospital Institutional Review Board.

All patients treated by radiochemotherapy (followed or not by pelvic surgery) were eligible. Most patients $(87 \%)$ underwent cisplatin-based $\left(40 \mathrm{mg} / \mathrm{m}^{2} /\right.$ week) chemoradiotherapy with a total dose of 45 to 50.4 Gy to the whole pelvis, and to the entire para-aortic lymph node chain for patients with para-aortic lymph node involvement. After whole pelvis external beam radiation therapy, all patients received pulsed dose rate brachytherapy, according to the GEC-ESTRO recommendations (17), and 32 patients underwent radical hysterectomy and pelvic lymphadenectomy. Pathological complete response was defined as the absence of any residual tumor after treatment. Follow-up visits were planned every 3 months after brachytherapy or definitive surgery for the first 2 years, then every 4 months for 1 year, every 6 months for the next 2 years, and annually after 5 years (median follow-up: 3.8 years; range: 3-162 months).

\section{Cell lines and reagents}

The A431 (squamous cell carcinoma) and CaSki (metastatic cervical cancer) human cell lines were from ATCC (Rockville, MD, USA) and cultured following ATCC recommendations. The MEHD7945A antibody was provided by Genentech, cisplatin was purchased from the hospital $(\mathrm{xxx})$.

\section{Ionizing radiation}


A linear particle accelerator was used (Varian Medical Systems; 6MV-photons; dose rates of 200UM/min and 400UM/min for in vitro and in vivo experiments, respectively) at the $\mathrm{xxx}$ Radiation Oncology Department. For combotherapy, MEHD7945A was added in vitro 4h before, and in vivo $24 \mathrm{~h}$ before IR.

\section{$\underline{\text { Clonogenic survival assay }}$}

The ability of MEHD7945A to radiosensitize A431 and CaSki cells was assessed using a standard colony-forming assay and growth curve analysis. Cells were trypsinized, washed, and seeded in triplicate in 6-well plates one day before IR. After exposure to IR (from 0 to $8 \mathrm{~Gy}$ ) and/or MEHD7945A $(1 \mu \mathrm{g} / \mathrm{ml}$ and $100 \mu \mathrm{g} / \mathrm{ml})$, cells were fixed with acetic acid: methanol (1:3) at different time-points (from 9 to 12 days post-treatment) and stained with Giemsa (Sigma Chemical Co., St Louis, MO, USA). MEHD7945A concentration was chosen on the basis of the results of the cell proliferation assay (see below). The survival fraction was calculated by counting the number of colonies containing at least 50 cells relative to the number of seeded cells, and multiplied by plating efficacy (number of counted cells relative to plating cells in untreated condition).

\section{Human tumor xenografts}

All in vivo experiments (minimun of 7 animals per group)were performed in compliance with the xxx regulations and ethical guidelines for experimental animal studies in an accredited establishment (Agreement No. C34-172-27). A431 cells $\left(1 \times 10^{6}\right)$ were injected subcutaneously in the right flank of 6-week-old female athymic nude Hsd mice (Envigo, Huntingdon, UK). Tumorbearing mice were treated with 2.5 or $10 \mathrm{mg} / \mathrm{kg}$ of MEHD7945 by intraperitoneally injection with or without IR ( 2 or 4 Gy), twice per week for 4 weeks. Tumor volumes were calculated with the formula: $D_{1} \times D_{2} \times D_{3} / 2$. 
Additional details about cleaved caspase 3 and Ki67 expression analysis in xenografts are in Supplementary Materials.

\section{Cell death analysis}

The Annexin A5 FITC/7-AAD Apoptosis Detection Kit (Beckman coulter, IM3614) was used according to the manufacturer's instructions to quantify apoptosis at $24 \mathrm{~h}$ and $48 \mathrm{~h}$ post-incubation with MEHD7945 (10 $\mu \mathrm{g} / \mathrm{ml})$, IR (one single dose of 2, 5 or 10Gy), or IR and MEHD7945. Data were acquired on a Gallios Flow Cytometer and analyzed with the Kaluza software (Beckman Coulter, Brea, USA).

Calreticulin membrane exposure was measured at $24 \mathrm{~h}$ and $48 \mathrm{~h}$ post-treatment (IR, MEHD1945A or combotherapy) using an anti-calreticulin antibody (Abcam, AlexaFluor® 647/ab196159, 1:200) and a Cytoflex cytometer (Beckman) with FlowJo 10 (Tristar). Additional details are in Supplementary Materials.

Supernatants were collected 24h, 48h and 72h after treatment (IR, MEHD1945A or combotherapy), centrifuged and pellets frozen. ATP release was detected using the ATPlite Luminescence Assay System (PerkinElmer®), according to the manufacturer's recommendations.

\section{Assessment of $\gamma \mathrm{H} 2 \mathrm{AX}$ by immunofluorescence}

Briefly, fixed cells were incubated with an anti-phosphorylated H2A.X ( $\gamma \mathrm{H} 2 \mathrm{AX}$; Ser139) antibody (1:200 in PBS-BSA, Millipore, 05-636). $\gamma \mathrm{H} 2 \mathrm{AX}$ foci were visualized using an epifluorescence Zeiss Imager 2 (Zeiss, Germany). The number of foci was counted in at least 100 cells. Additional details are in Supplementary Materials.

\section{Western blotting}


A431 and CaSki cells were lysed and expression of EGFR, HER3, ERK1/2, AKT, phosphorylated EGFR, HER3, ERK1/2 and AKT (antibodies from Cell Signaling Technology, Beverly, MA) assessed, as previously described (18). Equal loading was assessed with an antibody against GAPDH (Cell Signaling Technology). Band intensity was analyzed with a PXi imager (Syngene, Cambridge, UK).

\section{Cell proliferation assay and treatments' interactions}

The effect of the combination of IR, MEHD7945 and cisplatin on cell proliferation was evaluated using a sulforhodamine B (SRB) colorimetric assay, as already described (19). Growth inhibition was calculated based on the percentage of proliferating cells in treated samples relative to untreated cultures. Treatments' interactions were analyzed using dose-response matrices, according to the Bliss equation (20). Additional details are in Supplementary Materials.

\section{Statistical analysis}

Analyses of the correlation of EGFR/HER3 expression with survival included only patients with available data ( $\mathrm{N}=72$ patients). For clinical results, continuous variables were described using medians and ranges, and categorical variables with frequencies and percentages. The Fisher's exact test was used to compare the distribution of categorical variables. All tests were two-sided. OS and disease-free survival (DFS) were estimated using the Kaplan-Meier method, and median follow-up durations using the reverse Kaplan-Meier method. Survival curves were generated with their logrank tests. Variables, including prognostic factors, were selected for univariable analysis. Hazard ratios (HR) were presented with $95 \%$ confidence intervals (CI).

For preclinical results, data were presented as the mean \pm standard error of the mean (SEM) of triplicate experiments, if not mentioned otherwise. Groups were compared using the non-parametric Kruskal-Wallis test. Clonogenic survival was analyzed using a linear mixed model to explore the relationship between the surviving fraction and IR doses. IR doses, treatment group and their 
interaction were the variables included in the fixed part of the model. Random intercepts were considered to take into account the replicate effect inside the IR dose groups.

A p-value $<0.05$ was considered statistically significant; multiplicity of testing was not considered due to the exploratory nature of this study. Statistical analyses were performed using STATA 13.0 (StataCorp, College Station, TX, USA).

\section{RESULTS}

\section{EGFR and HER3 as biological targets in cervical cancer}

We first analyzed EGFR and HER3 expression in cervical cancer biopsies at diagnosis ( $\mathrm{n}=72$; one for each patient). EGFR was overexpressed (H-scores higher than 150) in 46 samples (63.0\%): $4.1 \%$ of FIGO stage IA2/IB1, $42.5 \%$ of FIGO stage IB2-IVA, and $16.4 \%$ of FIGO stage IVB tumors $(\mathrm{p}=0.018)$. HER3 was overexpressed (H-scores higher than 50) in 18 samples $(25.0 \%): 5.5 \%$ of FIGO stage IA2/IB1, $4.2 \%$ of FIGO stage IB2-IVA, and $15.3 \%$ of FIGO stage IVB tumors $(\mathrm{p}<0.001)$. EGFR and HER3 were concomitantly overexpressed only in seven of the 22 FIGO IVB cancer specimens (32\%) (Table 1). These seven patients had pelvic and para-aortic node involvement $(\mathrm{p}<0.001$; Table 1$)$. We did not find any correlation between tumor response or relapse and EGFR, HER3, or EGFR/HER3 co-expression.

Univariable analysis of common clinical prognostic factors showed that lymph node involvement, metastatic disease, and FIGO stage were significantly correlated with the patients' outcome (DFS and OS, Supplementary Table 1). As expected, due to the fact that all patients with EGFR/HER3 co-expression had a FIGO IV cancer, this co-expression was also significantly correlated with the 3-year OS $(\mathrm{HR}=4.27 ; 95 \% \mathrm{CI}=1.38-13.19 ; \mathrm{p}=0.006$. Fig. 1; Supplementary Table 1) and DFS $(\mathrm{HR}=4.23 ; 95 \% \mathrm{CI}=1.37-13.00 ; \mathrm{p}=0.006)$ (Supplementary Table 1). However, in multivariable analysis, only para-aortic lymph node involvement remained significantly correlated with outcome (DFS and OS, Supplementary Table 2). Nevertheless, in the FIGO IVB subgroup, the median OS 
was 14.6 and 23.1 months ( $\mathrm{p}=0.317$, Log-rank test) and the median DFS was 9.5 and 11.3 months ( $p=0.662$, Log-rank test) in patients with and without EGFR/HER3 co-expression, respectively.

\section{MEHD7945 increases the response to radiation in A431 cell tumor xenografts}

Then, to investigate whether the IR-MEHD7945A combination could be a relevant strategy, particularly for cervical cancer showing EGFR-HER3 co-expression, we used A431 and CaSki cells. Immunocytochemistry and cytometry (Supplementary figure 1) showed that HER3 was mildly expressed in both cells lines, whereas EGFR expression was stronger in A431 than in CaSki cells.

In mice xenografted with A431 cells (at least 7 mice/group), tumor volume was significantly reduced and the median survival increased after combotherapy (IR=4Gy; MEHD7945=10 mg/kg) compared with IR alone (63 versus 34 days; $p=0.079$ ) (Fig. 2A and supplementary figure 2A). Due to the high rate of radiation-induced toxicity (weight loss), we performed a second experiment using lower IR dose and antibody concentration (IR=2 Gy; MEHD7945A=2.5 mg/kg). Survival was significantly higher after combotherapy than IR alone (42 vs 28 days; p=0.0408) (Fig. 2B and supplementary figure 2B). Moreover, intra-tumor apoptosis (percentage of cleaved caspase 3positive cells) was higher in the combotherapy group compared with IR alone and untreated controls (Fig. 2C). Conversely, the fraction of KI67-positive cells was not significantly different (supplementary figure 2C).

Effect of combotherapy on cell survival, cell proliferation, DNA damage and EGFR/HER3 signaling

We then evaluated in vitro the combotherapy effects by measuring the clonogenic survival in A431 and CaSki cells after 10 days of exposure to MEHD7945A and/or IR (Fig. 3A). Compared with IR, the combination of MEHD7945A $(10 \mu \mathrm{g} / \mathrm{ml})$ with IR significantly reduced the surviving fraction ( $\mathrm{p}=0.004$ for $\mathrm{A} 431 ; \mathrm{p}<0.001$ for CaSki) while $1 \mu \mathrm{g} / \mathrm{ml}$ of MEHD7945A with IR did not have any 
effect ( $\mathrm{p}=0.334$ for A431; $\mathrm{p}=0.854$ for CaSki cells). In addition, the MEHD7945A $(1 \mu \mathrm{g} / \mathrm{ml})$ and IR (10Gy) combination had the strongest inhibitory effect on A431 and CaSki cell proliferation (cell number after $72 \mathrm{~h}$ of treatment) (Fig. 3B).

Analysis of DNA damage ( $\gamma \mathrm{H} 2 \mathrm{AX}$ foci) (Fig. 3C) indicated that the number of $\gamma \mathrm{H} 2 \mathrm{AX}$ foci per cell was significantly increased at $1 \mathrm{~h}$ after combotherapy compared with IR alone $(\mathrm{p}=0.0015$ for A431; $\mathrm{p}=0.0001$ for CaSki) or MEHD7945A alone $(\mathrm{p}<0.0001)$.

Finally, analysis of EGFR and HER3 signaling by western blotting (Fig. 3D and supplementary figure 3) showed that in untreated cultures, EGFR and HER3 phosphorylation levels were low in A431 cells and high in CaSki cells. In A431 cells, IR alone increased EGFR and HER3 phosphorylation starting at $15 \mathrm{~min}$ and until $240 \mathrm{~min}$ post-IR. Conversely, after co-exposure to IR and MEHD7945A, EGFR phosphorylation level was lower than in untreated cells, and HER3 phosphorylation was completely inhibited as well as MAPK and AKT phosphorylation. In CaSki cells, IR did not modulate EGFR and HER3 phosphorylation compared with untreated cells. Conversely, co-exposure to IR and MEHD7945A inhibited HER3, AKT and MAPK phosphorylation, but had no effect on EGFR phosphorylation. Finally, differently from the IRMEHD7945A combination that inhibited both the EGFR and HER3 pathways, the association of cetuximab and IR had only a slight effect on HER3 and AKT phosphorylation (supplementary figure 4).

\section{Combotherapy increases tumor cell death}

Analysis of early and late apoptosis in A431 cells exposed to IR (2, 5, or $10 \mathrm{~Gy}$ ) and/or MEHD7945A indicated that at 24h post-exposure, apoptosis was higher in cells incubated with MEHD7945A (mean=19.5\%) than in untreated cells $(\mathrm{p}=0.0209)$ and irradiated cells, regardless of the IR dose (from 6.5 to $10.5 \%$ ) (Fig. 4A). Conversely, at 48h, the apoptosis rates induced by 10Gy and MEHD7945A were comparable (27\%). Compared to IR, combotherapy increased both early and late apoptosis/necrosis rates, especially at $24 \mathrm{~h}$ and $48 \mathrm{~h}$ (Fig. 4A). We obtained similar results in 
CaSki cells (supplementary figure 5A). This effect was associated with an increase of cleaved

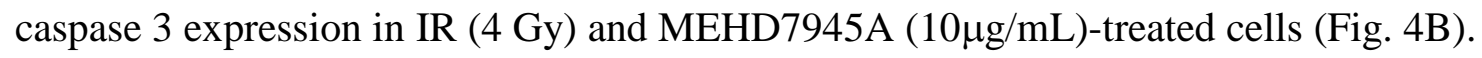

Then, to determine the immunogenic cell death role, we measured calreticulin exposure on the cell surface and ATP release. At 48h, calreticulin translocation was increased in A431 cells incubated with MEHD7945A alone $(1 \mu \mathrm{g} / \mathrm{mL})$, but not with IR alone (different doses) (Fig. 4C). The MEHD7945A and IR combination significantly increased calreticulin exposure, but only at high IR dose (10Gy). We obtained similar results in CaSki cells (supplementary figure 5B).

Compared with untreated cells, IR alone (but not MEHD7945A alone) significantly increased ATP release in a dose-dependent manner (Fig. 4D). Compared with IR alone, ATP release was increased at $24 \mathrm{~h}$ post-combotherapy, but not at later time points. These results suggest that IR and the combotherapy could induce immunogenic cell death.

\section{Association of irradiation, MEHD7945A and cisplatin}

As cisplatin-based chemotherapy combined with radiotherapy is the gold standard for cervical cancer, we assessed whether the combination of IR, MEHD7945A and cisplatin had a synergic or additive effect. After incubation of A431 and CaSki cells with increasing doses of IR, MEHD7945A and cisplatin for 5 days (Fig. 5), their combination had mainly an additive effect. 


\section{DISCUSSION}

Our study shows that EGFR and HER3 were co-expressed only in aggressive and advanced cervical cancer (FIGO stage IVB tumors). The too small number of EGFR- and HER-positive tumor samples did not allow determining whether their co-expression is a candidate prognostic marker, and in our series only para-aortic nodal involvement was an independent prognostic factor. In a recent large cohort of patients with cervical cancer $(n=401)$ and mainly treated by surgery alone (74\%), HER2 amplification (tissue micro-array analysis) was associated with poor patients outcome, but only tumor size, vascular space invasion and histologic type were independent prognostic factors (21). In the study by Fuchs and coworkers in which $50 \%$ of patients were treated by surgery alone and $33 \%$ by radiotherapy alone $(n=78)(6), 63 \%$ of tumor samples overexpressed EGFR and 74.4\% HER3 (HER1-4 co-expression was not studied). EGFR overexpression was associated with higher survival, and HER3 overexpression with poor survival. Conversely, a recent translational study within a phase II clinical trial found that tumor EGFR expression was not correlated with the treatment response or patient outcome (22). In our cohort, EGFR/HER3 coexpression was only observed in FIGO IVB cancer samples that are known to have a poor outcome. Yet, in the FIGO IVB subgroup, outcome seemed to be worse in patients with EGFR/HER3 coexpressing tumors. A larger cohort is required to confirm this finding and to limit the possible selection bias.

Besides the balance between HER1-4 receptors (6), patient outcome is influenced also by the presence of Human Papillomavirus (HPV) that regulates HER3 expression $(23,24)$. Fahkry and colleagues recently showed that persistent oral HPV DNA detection is associated with poor outcome in patients with HN cancer (25). The lack of data on HPV status is another limitation of our study in addition to the very small number of patients with tumors showing HER3 and EGFR co-expression.

Our preclinical results on the ability of MEHD7945A to radiosensitize EGFR/HER3-co-expressing cervical cancer cells lines are consistent with those previously reported in lung and HN cancers 
$(13,14)$. Compared with single treatments, MEHD7945A with IR induced efficiently calreticulin exposure and ATP release, suggesting that this combotherapy might trigger immunogenic cell death. Similarly, inhibition of EGFR interaction with cetuximab (alone or in combination with chemotherapy) induces calreticulin exposure (26), and anti-EGFR antibodies induce immunogenic apoptosis of tumor cells (27). In cervical cancer, radiochemotherapy has a significant role in immune response activation through immune cell activation within the local tumor microenvironment (28), and cisplatin also induces apoptotic tumor cell death in a JNK-dependent manner (29). As our results showed a synergic effect of the combination of a small dose of MEHD7945A, cisplatin and IR, their association could improve patients' outcome by increasing tumor control and by activating the immune response.

Although in the MEGHAN trial, the outcome of patients with recurrent/metastatic HN cancer who progressed after at least one line of cisplatin-based chemotherapy was not improved by MEHD7945A compared with cetuximab (30), McKnight and colleagues (31) suggested that EGFR and HER3 inhibition should be considered in patients resistant to EGFR treatment. As our results showed a synergic effect of the combination of MEHD7945A, cisplatin and radiotherapy, we propose to assess MEHD7945A as a radiosensitizer. Moreover, our data indicate that MEHD7945A could be effective at low dose. This might reduce the occurrence of adverse events when combined with radiochemotherapy, compared with the MEGHAN trial. Furthermore, it is well described that blocking one HER receptor can be compensated by activation of another HER family member, particularly HER3 that has been identified as a key contributor to resistance to anti-EGFR or -HER2 therapy (32). MEHD7945A capacity to overcome this type of resistance has been already reported for non-small lung carcinoma (14). We found that MEHD7945A combined with IR can inhibit HER3 signaling, particularly in CaSki cells that are derived from HPV-positive cervical cancer and in which basal HER3 phosphorylation is very high, probably due to a PI3KCA mutation that strongly induces HER3 and AKT activity. Conversely, EGFR phosphorylation was inhibited only in A431 cells, but not in CaSki cells that show high basal EGFR phosphorylation and harbor super- 
enhancers in the proto-oncogene EGFR (33). Despite this difference, the MEHD7945A-IR combination had a strong effect on cell viability and proliferation in both cell lines, confirming the importance of HER3 in MEHD7945A anti-proliferative effect.

The MEHD7945A-IR combination also increased cell apoptosis (both in vitro and in vivo) and $\gamma \mathrm{H} 2 \mathrm{AX}$ expression in A431 and CaSki cells. These results indicate that MEHD7945A promotes the radiation response by modulating DNA damage-induced cell death.

Finally, in HPV-positive HN cancer, HER3 overexpression is associated with worse prognosis, and HER3 targeting inhibits growth of HPV-positive cell lines (24). Furthermore, as the development of cervical malignant squamous cell lesions is commonly related to HPV infection, our preclinical and clinical results suggest the possible use of the MEHD7945A-IR combination in cervical cancer. These preliminary results should be confirmed in a larger sample before transfer to clinical development. 


\section{REFERENCES}

1. Eifel PJ, Winter K, Morris M, et al. Pelvic irradiation with concurrent chemotherapy versus pelvic and para-aortic irradiation for high-risk cervical cancer: An update of radiation therapy oncology group trial (rtog) 90-01. Journal of clinical oncology : official journal of the American Society of Clinical Oncology 2004;22:872-80.

2. Reducing uncertainties about the effects of chemoradiotherapy for cervical cancer: Individual patient data meta-analysis. The Cochrane database of systematic reviews 2010:CD008285.

3. Noordhuis MG, Eijsink JJ, Roossink F, et al. Prognostic cell biological markers in cervical cancer patients primarily treated with (chemo)radiation: A systematic review. International journal of radiation oncology, biology, physics 2011;79:325-34.

4. Perez-Regadera J, Sanchez-Munoz A, De-la-Cruz J, et al. Negative prognostic impact of the coexpression of epidermal growth factor receptor and c-erbb-2 in locally advanced cervical cancer. Oncology 2009;76:133-41.

5. Noordhuis MG, Eijsink JJ, Ten Hoor KA, et al. Expression of epidermal growth factor receptor (egfr) and activated egfr predict poor response to (chemo)radiation and survival in cervical cancer. Clinical cancer research : an official journal of the American Association for Cancer Research 2009;15:738997.

6. Fuchs $\mathrm{I}$, Vorsteher $\mathrm{N}$, Buhler $\mathrm{H}$, et al. The prognostic significance of human epidermal growth factor receptor correlations in squamous cell cervical carcinoma. Anticancer research 2007;27:959-63.

7. Lee CM, Shrieve DC, Zempolich KA, et al. Correlation between human epidermal growth factor receptor family (egfr, her2, her3, her4), phosphorylated akt ( $p$-akt), and clinical outcomes after radiation therapy in carcinoma of the cervix. Gynecologic oncology 2005;99:415-21.

8. Ocana A, Vera-Badillo F, Seruga B, et al. Her3 overexpression and survival in solid tumors: A metaanalysis. Journal of the National Cancer Institute 2013;105:266-73.

9. Campbell MR, Amin D, Moasser MM. Her3 comes of age: New insights into its functions and role in signaling, tumor biology, and cancer therapy. Clinical cancer research : an official journal of the American Association for Cancer Research 2010;16:1373-83.

10. Gala K, Chandarlapaty S. Molecular pathways: Her3 targeted therapy. Clinical cancer research : an official journal of the American Association for Cancer Research 2014;20:1410-6.

11. Contessa JN, Abell A, Mikkelsen RB, et al. Compensatory erbb3/c-src signaling enhances carcinoma cell survival to ionizing radiation. Breast cancer research and treatment 2006;95:17-27.

12. Li C, Brand TM, lida M, et al. Human epidermal growth factor receptor 3 (her3) blockade with u31287/amg888 enhances the efficacy of radiation therapy in lung and head and neck carcinoma. Discovery medicine 2013;16:79-92.

13. Li C, Huang S, Armstrong EA, et al. Antitumor effects of mehd7945a, a dual-specific antibody against egfr and her3, in combination with radiation in lung and head and neck cancers. Molecular cancer therapeutics 2015;14:2049-59.

14. Huang S, Li C, Armstrong EA, et al. Dual targeting of egfr and her3 with mehd7945a overcomes acquired resistance to egfr inhibitors and radiation. Cancer research 2013;73:824-33.

15. Juric D, Dienstmann R, Cervantes A, et al. Safety and pharmacokinetics/pharmacodynamics of the firstin-class dual action her3/egfr antibody mehd7945a in locally advanced or metastatic epithelial tumors. Clinical cancer research : an official journal of the American Association for Cancer Research 2015;21:2462-70.

16. Jimeno A, Machiels JP, Wirth L, et al. Phase ib study of duligotuzumab (mehd7945a) plus cisplatin/5fluorouracil or carboplatin/paclitaxel for first-line treatment of recurrent/metastatic squamous cell carcinoma of the head and neck. Cancer 2016.

17. Haie-Meder C, Potter R, Van Limbergen E, et al. Recommendations from gynaecological (gyn) gec-estro working group (i): Concepts and terms in $3 \mathrm{~d}$ image based $3 \mathrm{~d}$ treatment planning in cervix cancer brachytherapy with emphasis on mri assessment of gtv and ctv. Radiotherapy and oncology : journal of the European Society for Therapeutic Radiology and Oncology 2005;74:235-45.

18. Thomas G, Chardes T, Gaborit N, et al. Her3 as biomarker and therapeutic target in pancreatic cancer: New insights in pertuzumab therapy in preclinical models. Oncotarget 2014;5:7138-48. 
19. Ogier C, Colombo PE, Bousquet C, et al. Targeting the nrg1/her3 pathway in tumor cells and cancerassociated fibroblasts with an anti-neuregulin 1 antibody inhibits tumor growth in pre-clinical models of pancreatic cancer. Cancer letters 2018;432:227-236.

20. Greco WR, Bravo G, Parsons JC. The search for synergy: A critical review from a response surface perspective. Pharmacological reviews 1995;47:331-85.

21. Halle MK, Ojesina Al, Engerud H, et al. Clinicopathologic and molecular markers in cervical carcinoma: A prospective cohort study. American journal of obstetrics and gynecology 2017;217:432 e1-432 e17.

22. de la Rochefordiere A, Kamal M, Floquet $A$, et al. Pik3ca pathway mutations predictive of poor response following standard radiochemotherapy $+/$ - cetuximab in cervical cancer patients. Clinical cancer research : an official journal of the American Association for Cancer Research 2015;21:2530-7.

23. Paolini F, Curzio G, Melucci E, et al. Human papillomavirus 16 e2 interacts with neuregulin receptor degradation protein 1 affecting erbb-3 expression in vitro and in clinical samples of cervical lesions. European journal of cancer (Oxford, England : 1990) 2016;58:52-61.

24. Brand TM, Hartmann S, Bhola NE, et al. Human papillomavirus regulates her3 expression in head and neck cancer: Implications for targeted her3 therapy in $\mathrm{hpv}(+)$ patients. Clinical cancer research : an official journal of the American Association for Cancer Research 2017;23:3072-3083.

25. Fakhry C, Blackford AL, Neuner G, et al. Association of oral human papillomavirus DNA persistence with cancer progression after primary treatment for oral cavity and oropharyngeal squamous cell carcinoma. JAMA oncology 2019.

26. Pozzi C, Cuomo A, Spadoni I, et al. The egfr-specific antibody cetuximab combined with chemotherapy triggers immunogenic cell death. Nature medicine 2016;22:624-31.

27. Garrido G, Rabasa A, Sanchez B, et al. Induction of immunogenic apoptosis by blockade of epidermal growth factor receptor activation with a specific antibody. Journal of immunology (Baltimore, $\mathrm{Md}$ : 1950) 2011;187:4954-66.

28. Dorta-Estremera S, Colbert LE, Mahalakshmi Krishna NS, et al. Kinetics of intratumoral immune cell activation during chemoradiation for cervical cancer. International journal of radiation oncology, biology, physics 2018.

29. van der Sluis TC, van Duikeren S, Huppelschoten S, et al. Vaccine-induced tumor necrosis factorproducing t cells synergize with cisplatin to promote tumor cell death. Clinical cancer research : an official journal of the American Association for Cancer Research 2015;21:781-94.

30. Fayette J, Wirth L, Oprean C, et al. Randomized phase ii study of duligotuzumab (mehd7945a) vs. Cetuximab in squamous cell carcinoma of the head and neck (mehgan study). Frontiers in oncology 2016;6:232.

31. McKnight BN, Kuda-Wedagedara ANW, Sevak KK, et al. Imaging egfr and her3 through (89)zr-labeled mehd7945a (duligotuzumab). Scientific reports 2018;8:9043.

32. Gaborit N, Lindzen M, Yarden Y. Emerging anti-cancer antibodies and combination therapies targeting her3/erbb3. Human vaccines \& immunotherapeutics 2016;12:576-92.

33. Chen X, Loo JX, Shi X, et al. E6 protein expressed by high-risk hpv activates super-enhancers of the egfr and c-met oncogenes by destabilizing the histone demethylase kdm5c. Cancer research 2018;78:1418-1430. 


\section{FIGURE LEGENDS}

Figure 1: EGFR and HER3 are relevant targets in cervical cancer.

(A) Analysis of EGFR and HER3 expression by immunohistochemistry in LACC tumor biopsies collected at diagnosis; and (B) overall survival in patienst with LACC classified according to the tumor EGFR and/or HER3 expression $(\mathrm{n}=72)$.

Figure 2: The association of MEHD7945A with irradiation increases survival of mice xenografted with A431 cancer cells.

(A and B) Nude mice were xenografted subcutaneously with A431 cells and treated with MEHD7945A (MEHD), irradiation (IR) or combotherapy (MEHD+IR) twice per week for 4 weeks. Different doses of each treatment were tested (A and B). Tumor volumes are presented as the mean \pm SEM for each group ( $\mathrm{n}=12$ animal per group) and survival as Kaplan Meier curves. The number at risk at each time-point is shown. (C) After 4 weeks of treatment (MEHD7945A 2.5mg/kg; IR 2Gy), 4 mice were killed and tumors collected for cleaved caspase 3 analysis by immunohistochemistry.

Figure 3: Effect of the MEHD7945A and irradiation combination on the cell surviving fraction, cell proliferation, DNA damage and HER signaling in A431 and CaSki cells. (A) Clonogenic assay: A431 and CaSki cells were exposed to IR (from 0 to 6Gy) and to MEHD7945A (1 and $10 \mu \mathrm{g} / \mathrm{ml}$ ), and 10 days later, the surviving fraction was determined. (B) Cell proliferation assay: A431 and CaSki cells were exposed to MEHD7945A $(1 \mu \mathrm{g} / \mathrm{ml})$ and/or IR as indicated, and 3 days later they were counted. Data are the mean \pm SEM. (C) DNA damage in A431 and CaSki cells after exposure to MEHD7945A (10 $\mu \mathrm{g} / \mathrm{ml})$ and/or IR (2Gy) was assessed by quantifying the number of $\gamma \mathrm{H} 2 \mathrm{Ax}$ foci per cell. (D) Western blot analysis of the EGFR and HER3 pathways in A431 and CaSki after IR (4 Gy) alone or with MEHD7945A $(10 \mu \mathrm{g} / \mathrm{ml})$. 
Figure 4: The association of MEHD7945A with irradiation induces apoptosis and immunogenic cell death.

(A) Early and late apoptosis were analyzed by Annexin A5/7AAD staining in A431 cells at 24h and 48h post-treatment with MEHD7945A (1 $\mu \mathrm{g} / \mathrm{ml})$ and/or irradiation. (B) Cleaved and total caspase 3 expression by western blotting in A431 cells after exposure to MEHD7945A (10 $\mu \mathrm{g} / \mathrm{ml})$ and/or irradiation (4 Gy). GAPDH was used as loading control. Quantification of each protein band was normalized to GAPDH and then represented as fold-change relative to untreatd cells. (C and D) Immunogenic cell death analysis by quantifying calreticulin exposure on the cell surface (C) and ATP release (D) in A431 cells exposed to MEHD7945A $(1 \mu \mathrm{g} / \mathrm{ml})$ and/or irradiation. Results are presented as the fold-change relative to untreated cells.

Figure 5: Synergy of the association of irradiation, cisplatin and MEHD7945A.

A431 and CaSki cells were exposed to the association at the indicated concentrations for five days and then cell proliferation was measured using the SRB colorimetric assay $(n=3)$. Results are presented as the percentage relative to untreated cells. The interactions between the tested drugs were addressed using dose-response matrices. 
Table 1. Patients' characteristics

\begin{tabular}{|c|c|c|c|c|}
\hline & & $\begin{array}{c}\text { No } \\
\text { EGFR/HER3 } \\
\text { co- } \\
\text { expression } \\
(n=65)\end{array}$ & $\begin{array}{c}\text { EGFR/HER3 } \\
\text { co- } \\
\text { expression } \\
(n=7)\end{array}$ & $p$-value \\
\hline Age (years) & Median, [Min-Max] & $48[27-82]$ & $61[35-69]$ & 0.22 \\
\hline \multirow[t]{9}{*}{ Tumor FIGO stage } & IA2 & $1(1.5)$ & $0(0)$ & \multirow[t]{9}{*}{0.04} \\
\hline & IB1 & $9(13.9)$ & $0(0)$ & \\
\hline & IB2 & $1(1.5)$ & $0(0)$ & \\
\hline & IIA & $5(7.7)$ & $0(0)$ & \\
\hline & IIB & $25(38.5)$ & $0(0)$ & \\
\hline & IIIA & $2(3.1)$ & $0(0)$ & \\
\hline & IIIB & $3(4.6)$ & $0(0)$ & \\
\hline & IVA & $4(6.2)$ & $0(0)$ & \\
\hline & IVB & $15(23.1)$ & $7(100)$ & \\
\hline \multirow[t]{4}{*}{ Lymph node staging } & N0 & 30 & 0 & \multirow[t]{4}{*}{$<.001$} \\
\hline & Pelvic N+/para-aortic N0 & 16 & 0 & \\
\hline & Pelvic $\mathrm{N}+$ /para-aortic $\mathrm{N}+$ & 14 & 7 & \\
\hline & Missing & 5 & 0 & \\
\hline \multirow[t]{3}{*}{ Chemoradiotherapy } & Exclusive & $26(40.0)$ & $3(42.9)$ & \multirow[t]{5}{*}{0.003} \\
\hline & $\begin{array}{c}\text { Followed by definitive } \\
\text { surgery }\end{array}$ & $31(47.7)$ & $1(14.3)$ & \\
\hline & After surgery & $1(1.5)$ & $3(42.9)$ & \\
\hline \multicolumn{2}{|l|}{ Surgery first } & $7(10.8)$ & $0(0)$ & \\
\hline \multicolumn{2}{|l|}{ Missing } & 0 & 0 & \\
\hline \multirow{2}{*}{$\begin{array}{l}\text { Pathological response } \\
\text { to chemoradiotherapy } \\
\text { (histology on surgery } \\
\text { specimen) } \\
\mathrm{N}=32\end{array}$} & Complete & $15(46.9)$ & $0(0)$ & \multirow[t]{2}{*}{1.000} \\
\hline & Partial & $17(53.1)$ & $1(100)$ & \\
\hline
\end{tabular}


A.

\begin{tabular}{|c|c|c|}
\hline Co-expression EGFR / HER3 & $\mathbf{N}=\mathbf{7 5}$ & $\%$ \\
\hline EGFR $\leq 150 /$ HER3 $\leq 50$ & 16 & 22.22 \\
\hline$E G F R \leq 150 /$ HER3 $>50$ & 11 & 15.28 \\
\hline$E G F R>150 /$ HER3 $\leq 50$ & 38 & 52.78 \\
\hline EGFR $>150 /$ HER3 $>50$ & 7 & 9.72 \\
\hline Missing & 3 & \\
\hline
\end{tabular}

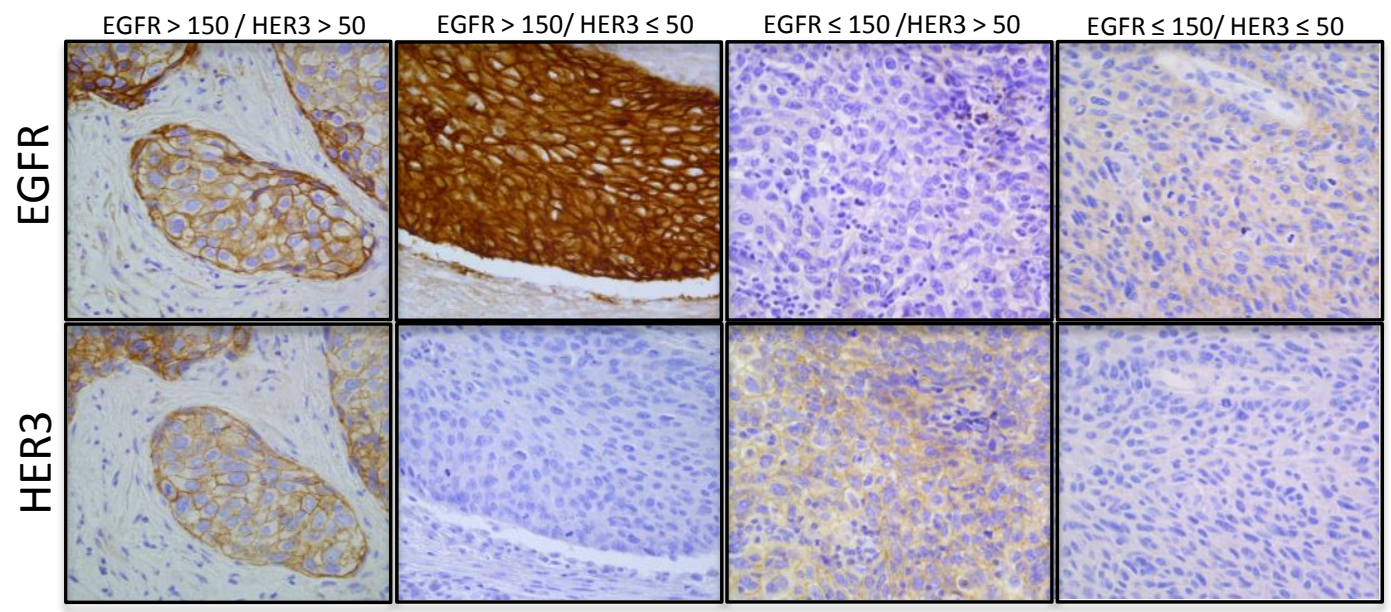

B.
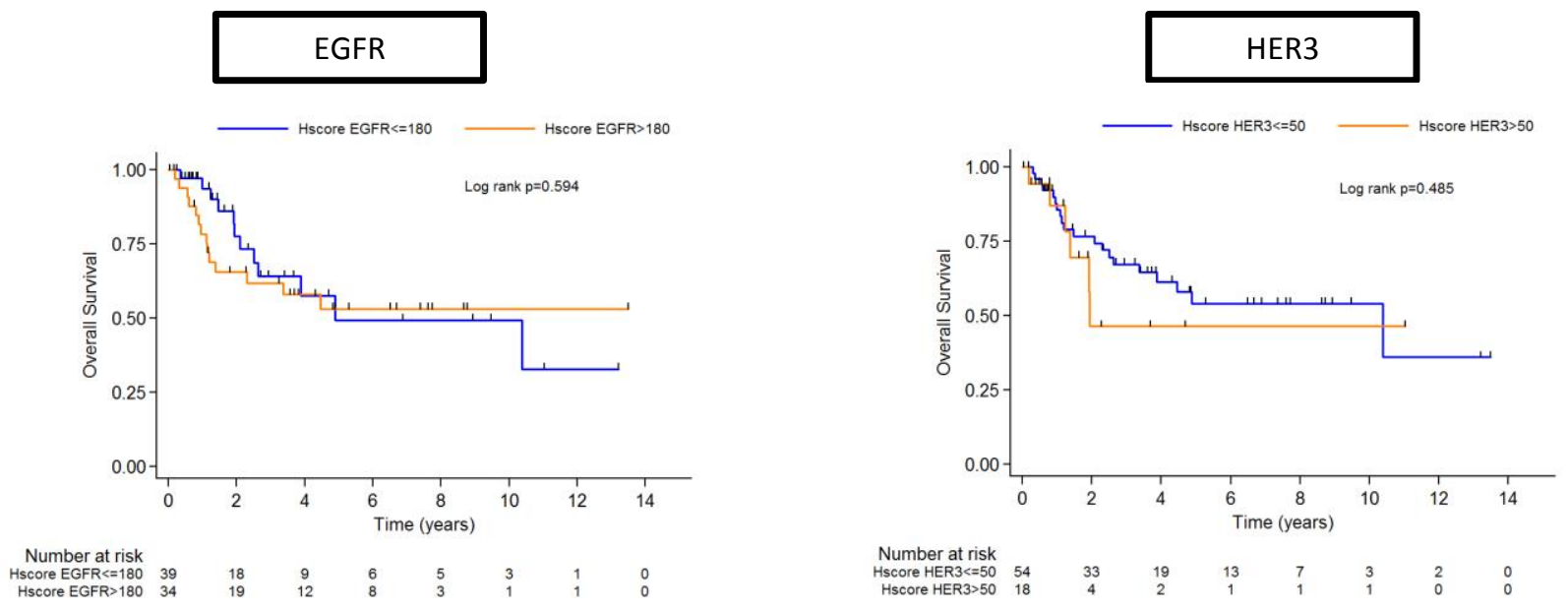

Co-expression

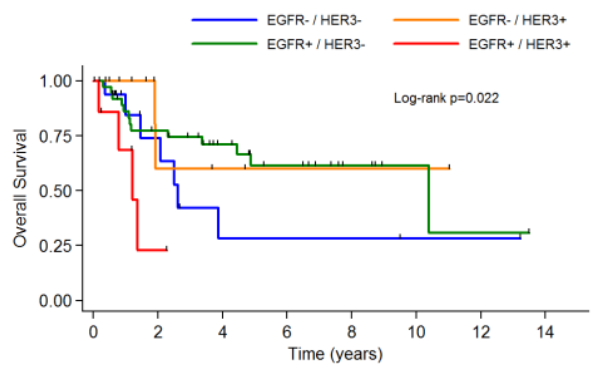

\begin{tabular}{ccccc}
\hline & Event & OS rate at 3 years & Hazard ratio & $95 \% \mathrm{Cl}$ \\
\hline EGFR / HER3 Co-expression & & & & \\
EGFR- / HER3- & $7 / 16$ & 42.2 & 1 & \\
EGFR-/ HER3+ & $2 / 11$ & 60.0 & 0.40 & {$[0.08 ; 1.91]$} \\
EGFR+ / HER3- & $13 / 38$ & 74.4 & 0.53 & {$[0.21 ; 1.33]$} \\
EGFR+ / HER3+ & $4 / 7$ & 22.9 & 2.60 & {$[0.73 ; 9.24]$} \\
& & & $p^{*}=0.022$ & \\
\hline EGFR / HER3 Co-expression & $22 / 65$ & 67.5 & 1 & \\
NEGATIVE & $4 / 7$ & 22.9 & 4.27 & {$[1.38 ; 13.19]$} \\
POSITIVE & & & $\mathrm{p}^{*}=0.006$ &
\end{tabular}

Number at risk 
(A) MEHD7945A (10mg/kg) and IR (4Gy)
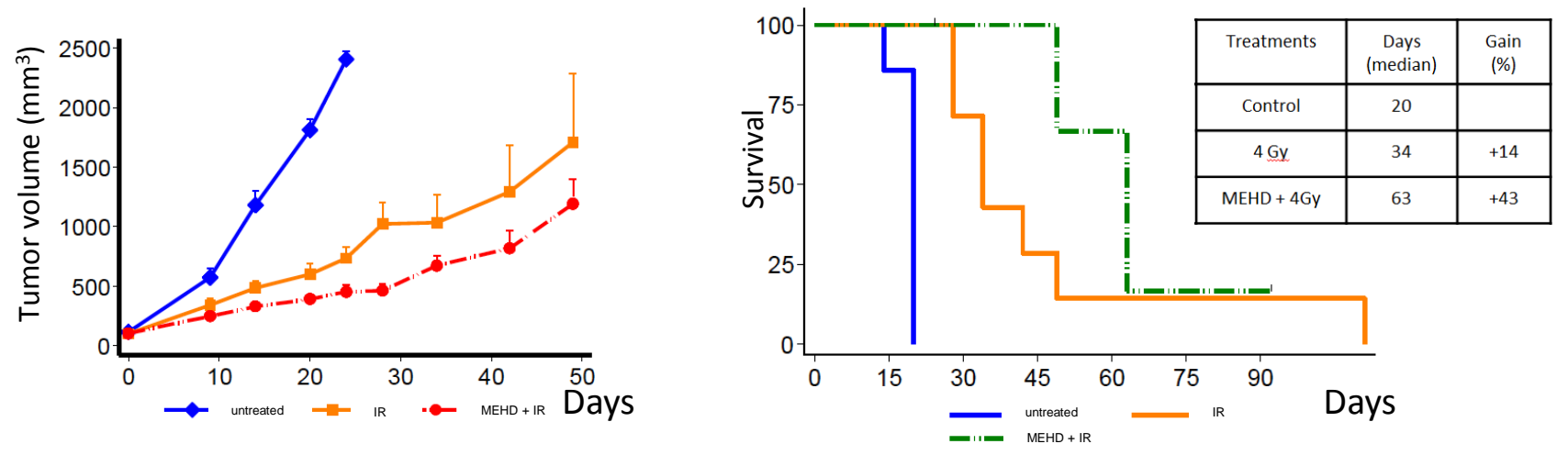

(B) MEHD7945A (2.5mg/kg) and IR (2Gy)

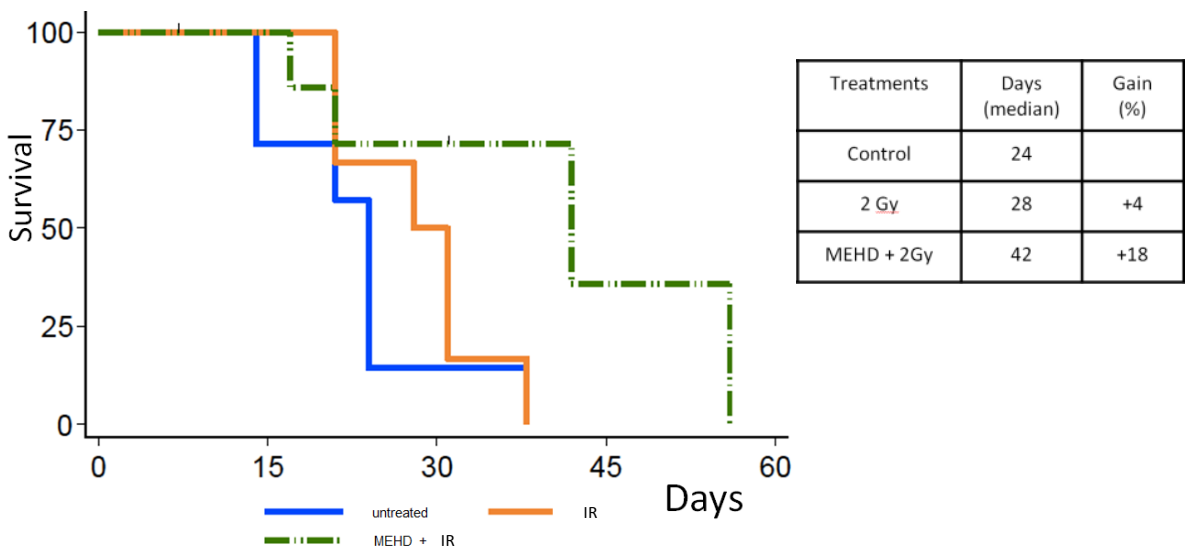

C Control IR
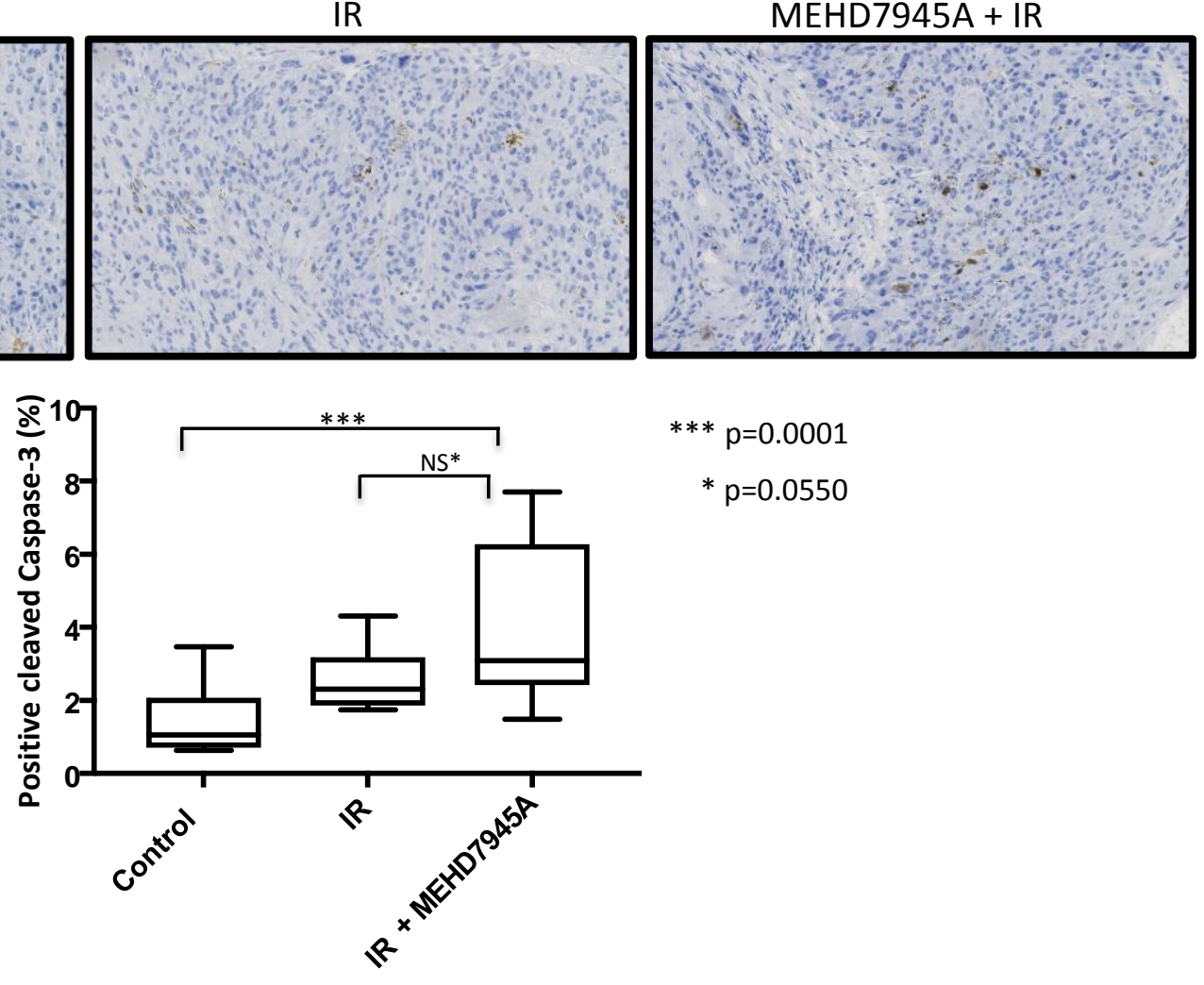
A
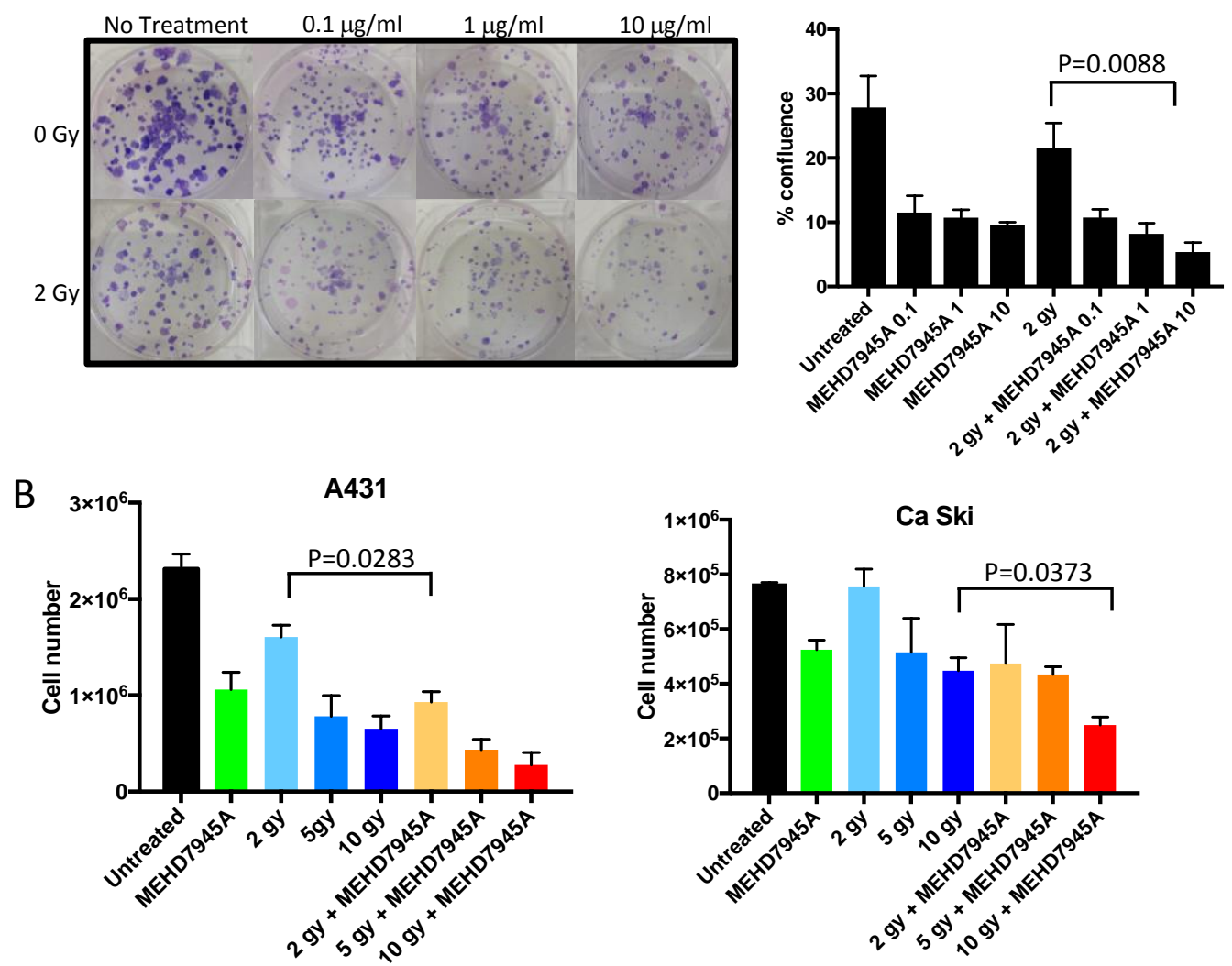

C

A431
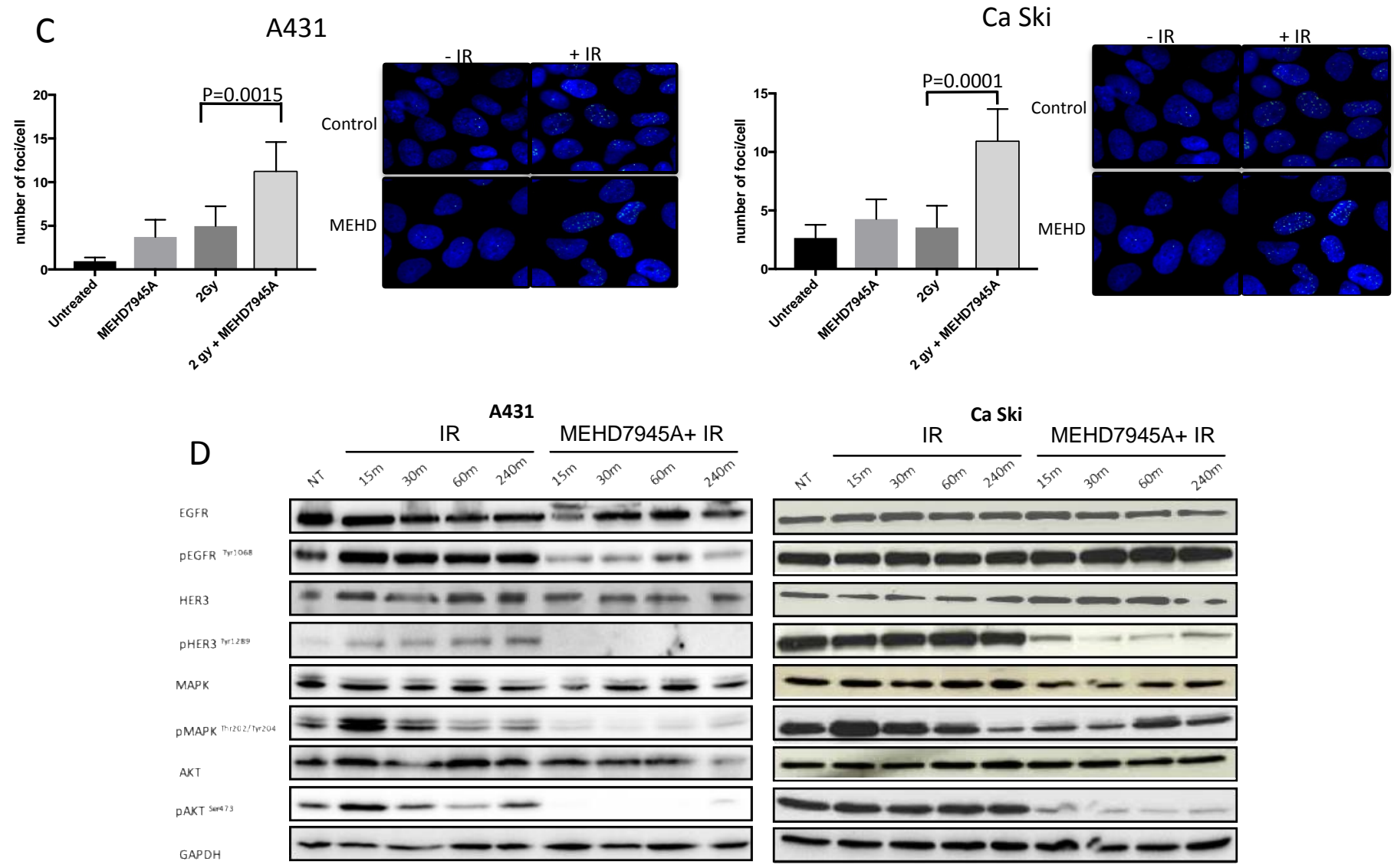

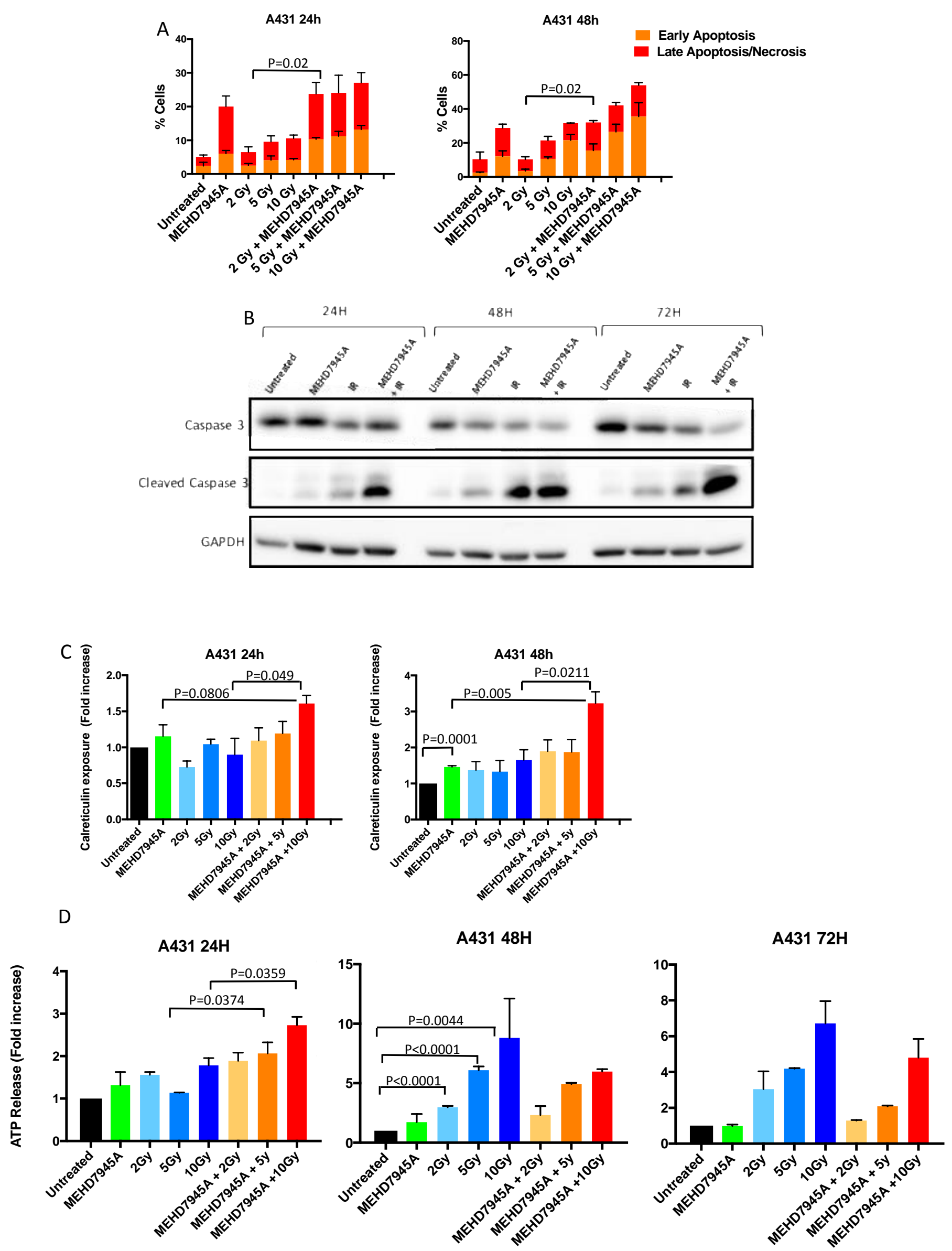
